\title{
Linkage disequilibrium in Huntington's disease: an improved localisation for the gene
}

\author{
RUSSELL G SNELL*, LAZARUS P LAZAROU*, SANDRA YOUNGMAN*, \\ OLIVER W J QUARRELL*, JOHN J WASMUTH†, DUNCAN J SHAW*, \\ AND PETER S HARPER* \\ From ${ }^{*}$ the Institute of Medical Genetics, University of Wales College of Medicine, Heath Park, Cardiff \\ CF4 4XN; and the Department of Biological Chemistry, California College of Medicine, University of \\ California, Irvine, CA 92717, USA.
}

SUMmaRY The search for the Huntington's disease gene has recently concentrated on the telomere of the short arm of chromosome 4 . The evidence suggesting this position has been based on single crossover events, but there is conflicting evidence regarding the position of the gene relative to the most terminal markers. We have found significant linkage disequilibrium between the markers D4S98 (probe BS731B-C) and D4S95 (probe BS674E-D) and HD, which supports a localisation for the gene proximal to $D 4 S 90$ and makes a telomeric localisation unlikely. This disequilibrium may also prove to be important in the future in allowing modification of risk estimates based on genetic linkage.

Since the localisation of the gene for Huntington's disease (HD) to the distal short arm of chromosome 4 by linkage to the DNA marker D4S10 (probe G8), ${ }^{1}$ a number of strategies have been used in order to obtain more closely linked markers. Most of these new probes have been placed on a physical map of the region. ${ }^{2}$ This map consists of three large regions of DNA: region 1 , the most proximal, contains the locus $D 4 S 10(\mathrm{G} 8)$, region 2, the central region, contains $D 4 S 95$ and $D 4 S 98,{ }^{34}$ and region 3 , adjacent to the telomere, includes $D 4 S 90$ (probe D5) ${ }^{5}$ and D4S141 (probe 2R3). ${ }^{6}$ The order of the markers has now been independently confirmed by the technique of radiation mapping. ${ }^{7}$ The majority of crossover data from family studies has placed the HD gene in the most distal region, close to the telomere. ${ }^{8}$ This has led to considerable efforts to clone in the region of the telomere and recently this was reported to have been achieved using a yeast artificial chromosome vector, ${ }^{9}$ raising the possibility that the HD gene may be contained within this clone.

Since studies based on single crossovers have yielded conflicting results, and because this approach becomes less informative the closer one approaches the gene, we have looked for linkage

Received for publication 3 August 1989. Accepted for publication 7 August 1989. disequilibrium between $H D$ and the linked DNA markers. The very low new mutation rate of HD is a necessary condition for the success of this approach. Negative results have already been reported for $D 4 S 10^{10}$ and we report here our findings for several other markers distal to this locus.

\section{Methods}

The HD patient samples studied were taken partly from families used for genetic linkage studies 51011 and partly from families who had requested genetic prediction. Seventy-six families were used for the study, not all families being informative with all the probes. All were of Caucasian origin, $47 \%$ being from Wales and the remaining $53 \%$ from various regions of England. The normal chromosomes used to establish non-HD allele frequencies were derived from spouses from HD families and the normal chromosome of affected subjects. The geographical origin of both HD patients and unaffected people was therefore similar.

\section{Results}

We have already reported that there is no linkage disequilibrium between $D 4 S 10$ and $H D^{10}$ (table). Similarly, there is no significant disequilibrium between $H D$ and either $D 4 S 90$ or $D 4 S 141$, two mar- 
TABLE Distribution of alleles for the markers D4S10, D4S95, D4S98, D4S90, and D4S141 in HD and normal chromosomes.

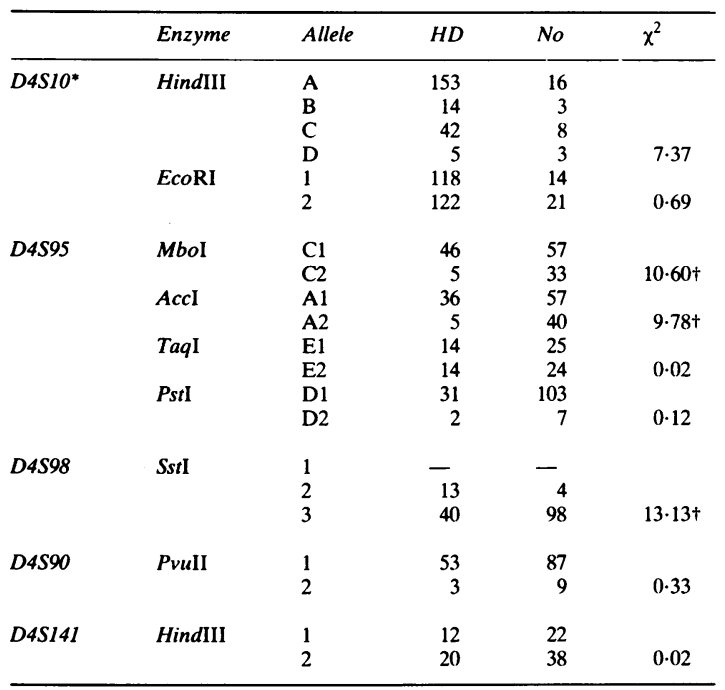

*The results shown for the probe G8 are those already reported by Youngman et al. ${ }^{11}$

$\dagger$ These are significant at $>99 \%$ level, that is, they show linkage disequilibrium with the Huntington's disease locus.

kers in the most distal region of $4 p$ lying within 300 $\mathrm{kb}$ of each other, and probably within $300 \mathrm{~kb}$ of the telomere (table).

For the markers $D 4 S 95$ and $D 4 S 98$ there is, by contrast, significant linkage disequilibrium. They are both located in the central region of the physical map, between $D 4 S 10$ and $D 4 S 90$, separated by approximately $1100 \mathrm{~kb}$, with $D 4 S 98$ being the more distal. The distance from this region to the telomere is not known exactly as the three regions have not been linked, but it is a minimum of $2000 \mathrm{~kb}^{2}$

Probe pBS674E-D (locus D4S95) detects five polymorphisms, one each with enzymes PstI, TaqI, and $M b o I$, and two with $A c c \mathrm{I}$. We have only used the simple two allele system detected by $A c c \mathrm{I}$ as it is difficult to interpret the five allele system, owing to the small $(100 \mathrm{bp})$ difference in allele size. Linkage disequilibrium is observed with $\mathrm{MboI}$ and $A c c \mathrm{I}$ but not with TaqI or PstI. The MboI and AccI polymorphisms are in almost complete linkage disequilibrium with each other. The HD gene segregates with alleles $\mathrm{A} 1(A c c \mathrm{I})$ and $\mathrm{C} 1(\mathrm{MboI})$ more frequently than expected, giving Yates corrected $\chi^{2}$ of 9.78 and 10.6 respectively, both significant at the $99 \%$ level (table).

Probe pBS731B-C (locus D4S98) detects a three allele polymorphism with SstI. One of the alleles only appeared in three patients and owing to the pedigree structure phase could not be established, so we treated the results as a two allele system for analysis. The HD gene segregates with allele 2 more often than expected resulting in a $\chi^{2}$ of $13 \cdot 13$, again significant at the $99 \%$ level.

\section{Discussion}

The detection of strong linkage disequilibrium between $H D$ and the loci $D 4 S 95$ and $D 4 S 98$ is of considerable significance for a number of reasons.

Firstly, it is directly relevant to the localisation of the HD gene and supports a localisation near to $D 4 S 95$ and $D 4 S 98$. The lack of disequilibrium at the more distal loci $D 4 S 90$ and $D 4 S 141$ also supports this conclusion. The distance from $D 4 S 98$ to the telomere is at least $2000 \mathrm{~kb}$ and taken together all of these results support a proximal location for $H D$ rather than one very close to the telomere as has been suggested. It is not possible to predict the position of the gene more accurately at present, though crossover data suggest that it is probably distal to $D 4 S 98 .^{8}$ We are currently walking from both probes looking for expressed sequences.

It is difficult to reconcile these new data with the evidence from single crossovers, the majority of which, although in total less than 10 , place the HD gene distal to all markers and consequently close to the telomere. ${ }^{8}$ Two possible explanations are that double crossovers are relatively common in this region, or alternatively that there is one very large gene or two genes involved and the particular population we have studied has only one mutation at the proximal locus. However, the use of disequilibrium mapping becomes more useful than the single crossover approach as one gets closer to the HD gene because it enables data from all families to be used rather than relying on a decreasing number of informative crossover events.

For linkage disequilibrium to be detected between two markers it is necessary that the markers are not only closely linked but also have very low mutation rates. The latter is known to be the case for $\mathrm{HD}$, but the mutation rates of various RFLPs are less well understood. Our results with D4S95 suggest that the $A c c I$ and $M b o I$ sites are relatively stable but that the TaqI and PstI sites may be mutable, and hence do not show disequilibrium even though physically very close to the other sites.

A second area of considerable interest will be to see if populations with a widely different frequency of HD (for example, Japan, Finland) show the same association as we have shown here, since this will bear directly on how many loci are involved and how many mutations exist. 
Thirdly, it should be possible in future to use disequilibrium information in genetic prediction, either in conjunction with genetic linkage data, or in isolation when pedigree structure is inadequate. We would stress however that the disequilibrium we have observed with D4S95 and D4S98 is not specific enough for HD chromosomes to allow this to be done at present and that our results may not prove applicable to all populations.

We would like to thank Dr Michael Morris, Miss Audrey Tyler, and Mrs Pat Jones for their help in obtaining blood samples and clinical advice, $\mathrm{Dr}$ Linda Meredith for making some of the results used here available, and Dr Jim Gusella for the G8 probe. We acknowledge the financial support of the Wellcome Trust and the Mental Health Foundation.

\section{References}

1 Gusella JF, Wexler NS, Conneally PM, et al. A polymorphic DNA marker genetically linked to Huntington's disease. Nature 1983;306:234-8.

2 Bucan M, Zimmer M, Whaley L, et al. Physical maps of 4p16.3, the area expected to contain the Huntington's disease mutation. Human Gene Mapping 10, 1989, A2560. Cytogenet Cell Genet (in press).

3 Smith B, Skarecky D, Bengtsson U, Magenis RE, Carpenter N, Wasmuth JJ. Isolation of DNA markers in the direction of the
Huntington disease gene from the G8 locus. Am J Hum Genet 1988;42:335-44.

4 Wasmuth JJ, Hewitt J, Smith B, et al. A highly polymorphic locus very tightly linked to the Huntington's disease gene. Nature 1988;332:734-6.

5 Youngman S, Sarfarazi M, Bucan M, et al. A new DNA marker (D4S90) is terminally located on the short arm of chromosome 4 , close to the Huntington's disease gene. Genomics (in press).

${ }^{6}$ Snell RG, Youngman S, Lehrach H, Sarfarazi M, Harper PS, Shaw DJ. A new probe (2R3) in the region of Huntington's disease. Human Gene Mapping 10, 1989, A2621. Cytogenet Cell Genet (in press).

7 Cox DR, Pritchard CA, Uglum E, Casher D, Kobori J, Myers RM. Segregation of the Huntington disease region of human chromosome 4 in a somatic cell hybrid. Genomics 1989;4: 397-407.

${ }^{8}$ MacDonald ME, Haines JL, Zimmer M, et al. Recombination events suggest potential sites for the Huntington's disease gene. Neuron (in press).

9 Bates G, Baxendale S, Sedlacek Z, et al. A telomere clone likely to contain the mutant form of the Huntington's disease locus. Human Gene Mapping 10, 1989, A2354. Cytogenet Cell Genet (in press).

10 Youngman S, Sarfarazi M, Quarrell OWJ, et al. Studies of a DNA marker (G8) genetically linked to Huntington's disease in British families. Hum Genet 1986;73:333-9.

"Harper PS, Youngman S, Anderson MA, et al. Genetic linkage between Huntington's disease and the polymorphism G8 in South Wales families. J Med Genet 1985;22:447-50.

Correspondence to R G Snell, Institute of Medical Genetics, University of Wales College of Medicine, Heath Park, Cardiff CF4 4XN. 